\title{
Assessing variations of extreme indices inducing weather-hazards on critical infrastructures over Europe -
} the INTACT framework

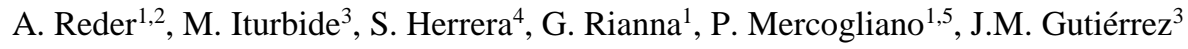 \\ (1) CMCC Foundation, Euro-Mediterranean Center on Climate Change, REMHI division, Capua, ITALY \\ (2) DICEA Dipartimento Ingegneria Civile Edile Ambientale, University Federico II, Naples, ITALY \\ (3) Grupo de Meteorología. IFCA (CSIC-Univ. Cantabria). Santander, SPAIN \\ (4) Grupo de Meteorología. Dpto. de Matemática Aplicada y C.C. Univ. Cantabria. Santander, SPAIN \\ (5) CIRA Centro Italiano Ricerche Aerospaziali, Laboratory of Meteorology, Capua, ITALY
}

\section{Corresponding author: A. Reder}

Mail: alfredo.reder@cmcc.it

Phone number: +390823623189

\begin{abstract}
Extreme weather events are projected to be more frequent and severe across the globe because of global warming. This poses challenging problems for critical infrastructures, which could be dramatically affected (or disrupted), and may require adaptation plans to the changing climate conditions. The INTACT FP7-European project evaluated the resilience and vulnerability of critical infrastructures to extreme weather events in a climate change scenario. To identify changes in the hazard induced by climate change, appropriate Extreme Weather Indicators (EWIs), as proxies of the main atmospheric features triggering events with high impact on the infrastructures, were defined for a number of case studies and different approaches were analysed to obtain local climate projections. We considered the influence of weighting and bias correction schemes on the delta approach followed to obtain the resulting projections, considering data from the Euro-CORDEX ensemble of regional future climate scenarios over Europe. The aim is to provide practitioners, decision makers and administrators with appropriate methods to obtain actionable and plausible results on local/regional future climate scenarios. Our results show a small sensitivity to the weighting approach and a large sensitivity to bias correcting the future projections.
\end{abstract}

Keywords: Critical Infrastructure; Extreme Weather Events; Bias Correction; Multi-model Ensembles; Climate probabilistic projections; Extreme Weather Indicators 


\section{Introduction}

Climate and weather events able to induce property damages, injuries and even casualties can be classified in terms of "rarity", "severity" and "rapidity" depending respectively on their frequency (rare or not rare), impact (severe or not severe) and longevity (acute, e.g. a major hurricane, or chronic, e.g. a major drought) (Stephenson 2008). Following this taxonomy, people and assets safeguarding in Europe has been recently affected by events with low occurrence probability (also if not ever on extreme tail of their distribution) and "severe" for exposure features of the impacted assets. Such events are usually defined as "Extreme Weather Events" (EWEs).

In the last years, the improvement of Critical Infrastructures (CIs) resilience to EWEs has drawn much interest, resulting as one of the most demanding challenges for government and society (EEA 2017; UNISDR 2015). According to the European Commission (EC 2008), "Critical Infrastructure is an asset, system or part thereof located in Member States which is essential for the maintenance of vital societal functions, health, safety, security, economic or social well-being of people, and the disruption or destruction of which would have a significant impact in a Member State as a result of the failure to maintain those functions".

The task to improve the CIs resilience is not trivial in "steady-state conditions" but it appears incredibly more challenging accounting for expected variations in hazard potentially induced by climate changes or in exposure for changes, e.g., in land use. Climate Change (CC) could induce very different variations in weather-related risks on CIs throughout Europe according to area, existing CIs and nature of the main hazards affecting directly (e.g. heat-waves, windstorms and heavy rainfalls) or indirectly (e.g. landslides, river and pluvial floods) the territories of interest (Ciervo et al. 2017; Rianna et al. 2017a,b).

There is then an obligation to revisit the risk posed to new and existing CIs and to develop practical (evidencebased) responses by risk-based techniques and a set of validated tools and data, tailored for practical needs, reflecting the level of the risk and the severity of the impact (social, economic, environmental, etc.) that would result in CIs failure due to EWEs. In this perspective, the role of administrators, policy-makers and CIs managers/operators is crucial. The task of communicating clearly the findings of climate projections and their uncertainty allowing all stakeholders to fully appreciate them is becoming more and more relevant for climate experts (Wilby 2017). Adequate "storytelling approaches" to explain how EWEs affect CIs should be defined and changes in their frequency and intensity should be identified to consider protection adaptation measures reflecting actual and predicted instances of CIs failures.

Within the climate community, the characterization of EWEs has been usually performed according to indices and extreme statistics (Wehner 2013). For moderate weather events, the investigation usually adopts indices, as those suggested by ETCCDI (http://etccdi.pacificclimate.org/list_27_indices.shtml), based on one or several weather parameters deemed to have the adequate information content in explaining the occurrence or magnitude of the EWE impacting the CI of interest. For much rarer phenomena, extreme value statistical theories have been widely adopted to assess EWE return periods in steady and non-stationary conditions potentially induced by $\mathrm{CC}$.

The INTACT FP7-European project addressed these challenges at the European level providing stakeholders with tools and methods to evaluate the resilience of CIs against threats due to CC, which combine climate and extreme weather, CI vulnerability and risk assessment, allowing for a highly focused analysis of a very specific issue with an extensive time, geographic and situation coverage. During the project, five case studies (namely Finland, Ireland, Italy, Netherlands and Spain) were considered. In this work, we focus on two case studies selected from the five proposed: (1) rainfall-induced landslide affecting the Campania region (Italy) with a special view on the Nocera municipality; (2) storms and heavy rainfall/winds in the Rotterdam port (Netherlands). Assuming the "steady-state" exposure and vulnerability of CIs in such areas, we investigate the potential variation in hazard due to $\mathrm{CC}$ considering the variation in EWEs impacting the CIs. In this perspective, we compare the effect of the different methods applied to obtain the CC projections, considering raw versus bias corrected data and weighted or equiprobable ensemble mean projections given by the regional climate models within the Euro-CORDEX program (Jacob et al. 2014).

This paper is organized as follows: Section 2 describes the test cases and defines the data and methods used, Section 3 summarizes the main results achieved and Section 4 introduces the conclusions and the good practices identified in the project.

\section{Data and Methods}

\subsection{Italian case study}




\subsubsection{Case study description}

The Italian case study deals with the rainfall-induced landslides (RILs) affecting the pyroclastic slopes of the Campania Region in South-Western Italy. Such phenomena are induced by the coupled effect of a period lasting several weeks-months, during which rainfall increases the soil saturation degree, acting as a predisposing factor, and a heavy and persistent rainfall event, acting as triggering factor (Pagano et al 2010). In recent years, the vulnerability of Campania to RILs was emphasized by the events occurred near Salerno and Naples, resulting in casualties and damages to infrastructures and buildings and that were exacerbated by the complex social and economic conditions of the area. The most important CIs potentially affected by RILs are represented by multimodal transport (railways, motorways and roads) and linear service infrastructures (water and electric networks) which densely cross the region.

Among the different geomorphological contexts of the Campania, this study considers the slopes forming Lattari Mts, around the Nocera Inferiore municipality. Since 1960, such slopes were affected by several RILs (1960, 1972, 1997 and 2005) entailing casualties and CIs interruptions/disruptions especially on the Naples-Salerno highway (Pagano et al 2010; Reder et al 2018). On such area, Reder et al (2016) and Rianna et al (2017a) provided an assessment of future variations of landslide activity under the potential CC effect using the climate simulation chain formed by the GCM (General Circulation Model) CMCC-CM dynamically downscaled through the RCM (Regional Climate Model) COSMO-CLM simulation at resolution of $8 \mathrm{~km}$ in the configuration optimized by CMCC for Italy (Bucchignani et al.2015, Zollo et al 2015). Both works project a substantial increase in potential RILs occurrence even if adopting a single climate simulation chain realization does not allow assessing the uncertainties associated with such projections; however, the added value of this higher resolution model emerges in terms of performances for temperature and precipitation with respect to the current EURO-CORDEX high resolution models.

\subsubsection{Extreme Weather Indicators (EWIs)}

According to literature and regulation indications, several precipitation-based extreme weather indicators (EWIs) are identified for this case study. During the project meetings with stakeholders, such EWIs were widely debated and their significance for CI operators and Administrators was verified. Specifically:

- Rx1day: annual maximum 1-day precipitation [mm];

- RT(REWS): return time associated with Rx1day(RT10y) - 10 years return time of Rx1day currently assumed by the Regional Early Warning System (REWS) of the Civil Protection as alarm thresholds; such index allows evaluating the potential recurrence of alarm threshold over future period [years];

- $\quad$ ET(R1-R59): number of exceedances of the R1-R59 empirical rainfall threshold proposed by de Vita and Piscopo (2002); the Authors assume the cumulative antecedent precipitation on 59 days (R59) as a predisposing factor and the daily rainfall (R1) as the trigger for landslide events in Lattari Mts area [number of occurrences].

\subsubsection{Observation data}

Daily rainfall data over 1981-2010 are obtained from two weather stations located near Nocera. The first station records daily precipitation from 1950 to 1999; the second one, installed after the 1997 RIL, records precipitation with time resolution of 10 minutes (aggregated in this work at daily resolution) and covers the period from 1998 to 2010 . The consistency of the dataset obtained by joining these observations is assessed through homogeneity tests.

\subsection{Netherlands case study}

\subsubsection{Case study description}

The Netherlands case study deals with the effects of EWEs on the Rotterdam port (van Ruiten et al. 2016). The port is located in a delta area close to urban and industrial complexes. It represents a key economic centre with several types of CIs (multimodal transport infrastructures, power supply and telecommunication networks, emergency coordination centres, industries and hospitals), which could be affected directly or indirectly by different types of EWEs. This complexity entails a cascading effect with ramifications at regional, national and international scales, which could negatively involve the market position of the Rotterdam port, should the disruption frequency due to EWEs increase in the future.

Based on the risk assessment analysis performed in close coordination with the operators acting on the territory, the EWEs affecting the Rotterdam port can be diverse and different types of hazards can be identified yielding short and long-term effects. For short-term effects, common problems can originate from storms and heavy rainfall potentially inducing local flooding, leading to disruptions in the port and transport operations, damages 
and power outages, and/or the temporary closure of the port. Moreover, EWEs with long lasting disruption (more than one week) can interrupt trade to the international hinterland (e.g. preventing raw materials for German steel industry to be shipped). Long-term effects, with more frequent disruptions, may worsen the market position of the Rotterdam port.

\subsubsection{Extreme Weather Indicators (EWIs)}

According to the investigation of recent past events and experience of the local stakeholders involved in the project, precipitation- and wind-based EWIs are identified for the Rotterdam port. Specifically:

\section{Precipitation-based EWIs}

- Rx1day: annual maximum1-day precipitation [mm];

- $\operatorname{Rx} 1$ day $(\mathrm{RT}=10 \mathrm{y}): 10$ years return value of highest 1-day precipitation $[\mathrm{mm}]$;

- $\operatorname{Rx} 1$ week $(\mathrm{RT}=10 \mathrm{y})$ : 10 years return value of highest 1 -week precipitation $[\mathrm{mm}]$;

Wind-based EWIs

- FGx1day: annual highest 1-day wind speed [m/s]

- FG17: number of days per year when the wind speed is higher than $60 \mathrm{~km} / \mathrm{h}$ (about $17 \mathrm{~m} / \mathrm{s}$ ) [number of days];

- FG33: number of days per year when the wind speed is higher than $120 \mathrm{~km} / \mathrm{h}$ (about $33 \mathrm{~m} / \mathrm{s})$ [number of days].

\subsubsection{Observation data}

Daily rainfall and wind speed data for the Rotterdam case study are obtained from the Royal Netherlands Meteorological Institute (KNMI) website, for the period 1981-2010.

\subsection{Model data}

Ten regional climate models from the Euro-CORDEX initiative at the highest resolution over Europe (about $0.11^{\circ} \sim 12 \mathrm{~km}$ ) are adopted to assess the potential variations of the EWIs selected (Table 1). As forcing for climate models, the Representative Concentration Pathways (RCP) 4.5 and 8.5 are considered (Mainhausen et al. 2011). The study is performed assuming the period 1981-2010 as reference for current condition and 2011-2040, 2041-2070 and 2071-2100 as indicative for future conditions respectively for near, medium and long-time horizons.

\subsection{Methods}

\subsubsection{Multi-model ensemble: Ensemble Averaging (EA) and Reliability Ensemble Averaging (REA)}

The use of multi-model climate projections allows a "probabilistic approach" to quantify the uncertainties in the EWI projections under future climate scenarios used for impact assessment. Many scientific works proposed probabilistic approaches with different complexity, assumptions and conceptual models, which are however generally difficult to figure out and implement for practitioners and users. For these reasons, in our analysis, we adopt a "semi-probabilistic approach" based on a quantitative method to combine output from multi-model simulations and a probabilistic method to assess the probability of exceeding a given threshold (Giorgi and Mearns 2003).

Regarding the quantitative part, there are two general approaches for the problem of combining output from multi-model simulations (Knutti et al 2010).

The first approach treats all the models equally under the assumption that "the individual components of the multi-model ensembles are realistic and equally likely representations of climate" (Raisanen and Palmer 2001). This approach, named EA (Ensemble Averaging), estimates the variation of a generic EWI through the direct average of all the model simulations, assigning the same weight to each model and neglecting a reliability criterion. It is a useful tool for analyses in which there are not observed data series for the selected indicators.

The second approach assumes that some models are "better" than others and the "best" models should receive more weight when the models are combined (Sham Bhat et al 2011). Among the different methodologies/methods based on this criterion, the REA (Reliability Ensemble Averaging; Giorgi and Mearns 2002) weights the output from multi-model ensembles according to model performance and scenario consistency. This approach requires the availability of local observations for the target EWIs on the area under investigation. 
Regarding the probability part, for both approaches the probability of a CC exceeding a certain threshold is given by the sum of the weights associated with models estimating an equal or higher variation over the total summation (for the EA all weights are equal to one).

More details about EA, REA and probabilistic part are reported as Supplementary material.

\subsubsection{Bias correction}

If available, daily observations can be adopted to reduce the systematic biases in climate simulations through bias correction approaches (Maraun 2016). Such step is crucial for analyses requiring the assessment of variations in absolute thresholds (e.g. the FG17 index of the Netherlands case study or for evaluating the variations in rainfall thresholds regulating the slope failure related to slope hydro-mechanical dynamics). Generally, bias correction approaches are based on a transfer function relating the observed and simulated daily distributions over a common reference period (see the Appendix of Gutiérrez et al 2017). Among the different bias correction methods, in this work we consider a non-parametric approach based on the observed and simulated empirical quantiles (Villani et al. 2015). Assumptions, constraints and added uncertainties of such approaches need to be clearly illustrated to the users (Maraun et al 2017).

\subsubsection{Levels of analysis adopted within the INTACT framework}

Based on the local information availability and the above methodologies, three levels of analysis are proposed:

A. only model projections are available: use the EA for evaluating variations without possibility of checking model performances and scenario consistency

B. observed synthetic data for the selected EWIs are available (e.g. data about maximum values): use the REA to evaluate variations, allowing to check model performances and scenario consistency.

C. observed daily data for the weather variables required by EWIs are available: the REA approach can be used; moreover also "absolute values" (e.g. physically based rainfall thresholds) through the adoption of bias correction approaches can be considered.

\section{Results}

\subsection{Italian case study}

\subsubsection{Potential variations of Rxlday over the Campania region}

A preliminary picture about the potential variations of precipitation-based EWIs for the Italian case study is obtained considering the Level A analysis and assessing the anomalies of Rx1day on the whole Campania Region (Figure 1). The analysis is performed using as input the RCP4.5 Euro-CORDEX raw projections over current and long-time horizon and obtaining as output for each grid point the EA anomalies (Figure 1a) and relative uncertainty range (Figure 1b). In the most RILs susceptible areas (south-western zone), the EA points out a smooth increase of the future Rx1day compared to the current Rx1day, with values ranging between 5 and $15 \%$. Regarding the uncertainty range, the analysis displays values between -5 and $5 \%$, as a lower bound, and values between 15 and $30 \%$ as an upper bound.

\subsubsection{Potential variations of EWIs for the Nocera Inferiore municipality}

To quantify the potential variations in RILs occurrence for the Nocera Inferiore municipality, the EuroCORDEX raw projections for $3 \times 3$ grid points surrounding the target area are post-processed using Level C analysis assessing variations in absolute rainfall thresholds returned by accounting for the actual hydrological slope response.

Figure 2 shows the results of bias correction over the current period for the Rxlday index. Except one simulation, raw models underestimate the Rx1day. As expected, this underestimation is mostly corrected once the bias correction method is applied.

The bias corrected projections are adopted to assess the EWIs potential variations considering separately RCPs over the three investigated future horizons. For each EWI, the procedure consists in quantifying the absolute value of weighted multi-model mean (WMMM) to obtain a synthetic indication about magnitude and direction of potential variation and assessing the variations in estimation using a probabilistic approach. 
Results are reported in Figure 3. In each box, the cumulative distribution function of anomalies and the probability associated with the WMMM are reported, showing in red and blue shaded areas the drier and wetter conditions, respectively, compared to the actual ones.

In terms of Rx1day (Figure 3a-3b), an increase in WMMM is projected for both RCPs; in any case the WMMM does not match the value at $50 \%$ of the exceedance probability corresponding to the median value of the probabilistic distribution due to the relative weight of the simulations involved in the analysis. Under RCP4.5, the severity is function of the time horizon following the expected increase in precipitable water due to atmosphere warming (O'Gorman 2009) while, under RCP8.5, many simulations provide the highest increases in the intermediate period, probably because of counter-feedbacks (e.g., soil drying).

Regarding the potential variation in RT(REWS) (Figure 3c-3d), a decrease in WMMM is projected for both RCPs; this reduction is higher for RCP8.5 with values up to about $-55 \%$ for the medium and long-time horizon. This implies that the REWS alarm threshold could be potentially crossed each $4.5 \mathrm{y}$ compared to the current condition (10y). As a result, a potential worsening of the safety conditions for RILs is projected in the Nocera area. In this case, the evaluation of anomalies involves as additional element of uncertainty the use of the extreme value statistical model.

Finally, also in terms of ET(R1-R59) (Figure 3e-3f), an increase in the conditions favourable to landslide triggering is projected for both RCPs. Compared to the current condition (75events/30years), the number of events potentially crossing the R1-R59 threshold increases slightly for RCP4.5 over the near-long horizon while it attains 96 and 102 respectively over medium and long-time. For RCP8.5, it could not vary until the medium and long-time horizon in which it increases from 96 to about 99, leading to a worsening of the slope stability conditions. For ET(R1-R59), the REA with bias correction may be the only suitable approach since the physically-based R1-R59 threshold requires absolute values as input data.

\subsubsection{Comparison between the levels of analysis adopted within the INTACT framework}

To assess the main differences arising between the Levels of Section 2.4.3, the variations of Rx1day are also quantified considering the uncalibrated projections and adopting both the EA (Level A) and the REA without bias correction (Level B). Figure 4 show this comparison for both RCPs over the long-time horizon.

The figure shows that the expected variations in maximum daily precipitation yield generally an increase compared to the current conditions. The results are quite similar for the EA approach (Level A) and the REA without bias correction (Level B), whereas major differences are observed when considering the REA after bias correction (Level C). Comparing Level A and B, weighting simulations tend to shift the WMMM to the median value reducing the effect of simulations which do not provide projections consistency with the other ones. Comparing Level B and C, bias correction projections yield higher relative variation of Rx1day. These variations involve the steps both as exceedance probability, tuned by the weights yielded by analysis, and as relative variation. In this sense the bias correction could induce significant variations in anomalies yielded by each model (Maraun et al 2017), especially for analysis focusing on the evaluation of extreme events (tail of probability distribution). This might involve, for example, the occurrence of out-of-range future events for which the calibration on this could generate unquantifiable approximations. At present, in this work, for all off-range values, the correction is performed on the highest percentile observed. The additional uncertainties associated with the further element of the simulation chain must be clear to the practitioners.

\subsection{Netherlands case study}

\subsubsection{Potential variations of Rxlday and FGxlday over a large domain in Netherlands}

As performed for the Italian case-study, a first frame is obtained assessing the anomalies of Rx1day (Figure 5a5b) and FGx1day (Figure 5c-5d) over a larger domain in the Netherlands. For Rx1day, the EA returns a widespread increase with values ranging between 5 and 20\%. The grid points located in the coastal area project the greatest increase. Moreover, the analysis of the uncertainty range displays a considerable variability, with values that generally range between -5 and $35 \%$ reaching in some cases also $40-45 \%$. For FGx1day, the EA returns a slight reduction with values ranging between -4 and $0 \%$. This reduction is less pronounced in the coastal area. The analysis of the uncertainty range displays a smooth variability of such EWI, with values between -6 and $4 \%$. The upper bound is projected in the coastal area. The largest uncertainty of the coastal areas is related with slight differences between the landmask considered for each RCM which strongly affects the physical process solved by the RCM.

\subsubsection{Potential variations of EWIs for the Rotterdam port}


The availability of local data allows performing Level $\mathrm{C}$ analysis, considering the Euro-CORDEX raw projections for $4 \times 4$ grid points surrounding the Rotterdam port. Since the EWIs for this test case are selected according to the experience of the local stakeholders and their expert judgement, a pre-analysis of observed data is performed to evaluate the relevance of each indicator selected. As a result, no values of wind speed exceeding the suggested thresholds (FG17 and FG33) are found in the observations and then these indicators cannot be considered. In fact, the datasets show how such values are attained by coastal winds occasionally for a few hours during a day, but do not represent mean daily values. Therefore, only the FGx1day is adopted as proxy of windinduced threats. This finding is very significant as it highlights the effect of the practitioners' perception on the identification of appropriate and physically plausible EWIs.

Figure 6 depicts the results of the bias correction over the current period for Rx1day (Figure 6a) and FGx1day (Figure 6b). In terms of Rx1day, all the RCMs present a similar bias, lower than for the Italian case study (Figure 2). As for the Italian case, the bias correction reduces the underestimation of RCMs and the differences between RCMs. The same result is achieved when the FGx1day is bias-corrected.

Figure 7 shows the EWIs projections for both RCPs over the three future horizons on the Rotterdam port. The results are plotted, as for the Italian test case.

In terms of Rx1day(RT10y) (Figure 7a-7b), an increase is expected for both RCPs. For RCP4.5, the WMMM is basically the same for all the time horizons (about 20-25\%) whilst for RCP8.5 the pattern highlights a worsening from the near to the long-time horizon with values up to 45\%. All the RCMs induce such worsening in terms of Rx1day(RT10y). Also in this case the anomalies evaluation involves as uncertainty element the adoption of extreme value statistical model.

Regarding the Rx1week(RT10y) (Figure 7c-7d), also in this case an increase is projected for both RCPs, but this time such trend is not returned by all the RCMs. For RCP4.5, the WMMM exhibits variations of 10-20\% while for RCP8.5 a $25 \%$ increase is returned with an exceedance probability of $30 \%$.

The last index involves the variations of FGx1day (Figure 7e-7f). For such index, slight variations are expected with WMMM less than $2 \%$ for both RCPs. Since a moderate variation of such indicator is projected, storms and heavy rainfall/winds in the Rotterdam port can be treated using only precipitation-based EWIs and the analysis of Rx1day(RT10y) and Rx1week(RT10y) points to a potential worsening of safety conditions compared to the current situation.

\section{Summary and Conclusions}

This work summarizes the procedures developed in the INTACT FP7-European project to assess how changes in frequency and/or intensity of EWEs potentially associated with CC could affect CIs. This synthesis is performed through a detailed description of two among the five test cases considered in the project: the landslides and storms respectively in Italy and Netherlands. Such cases are selected due to the great involvement of stakeholders in all the analysis steps (indicators selection, results analysis, evaluation of protection countermeasurements).

On the one hand, we define diverse levels of analysis based on the requirements of the impact study and of local data availability. On the other hand, we analyse the regional CC signals for some representative EWIs considering both equiprobable members and a weighting approach, and after and before bias-correcting the data. To this aim, we test the influence of weighting and bias correction schemes on the delta approach followed to obtain the resulting projections, considering data from the Euro-CORDEX ensemble of regional future climate scenarios over Europe.

Our results show a generalized increment in the intensity of the EWIs considered, more relevant for the precipitation-based indices, leading to a worsening in hazard for both case studies, which depends on the scenario (RCP4.5/8.5) and period (2011-2040/2041-2070/2071-2100) considered. In addition, a small sensitivity to the weighting approach and a large sensitivity to bias correction in the future projections is found for the case studies and EWIs considered. As shown, all the RCMs are affected by biases, independently of the variable, scenario or region considered, so the uncertainty associated with the bias correction process should be considered in any impact study, mainly when indices based on absolute thresholds are required.

Considering framework, methodologies and results, the activities developed within the INTACT project poses a theory-based starting point for CI owners, operators and policy-makers for the set-up of protection systems against present and future climatic hazard features. This work defines the procedures to properly obtain, analyse and translate the changes projected by the climate models into information adequate for the CI owners. In this sense, the observed data analysis helps determine wisely the alarm threshold of a specific CI for the selected indicator, and the probabilistic approach, applied to this indicator, returns a greater flexibility and the 
opportunity to choose carefully the levels of uncertainty associated with the indicators considering both current and future conditions.

The procedure tries to suggest a way to bridge the gaps between $\mathrm{CC}$ adaptation and disaster risk reduction through the adoption of simple but effective probabilistic approaches. In this perspective, improving the coherence between the two targets, reducing duplication in efforts represents a key point in EU policies (EEA 2017). Finally, the proposed methodology can be generalized for any type of extreme event.

\section{Acknowledgments}

This work has been carried out within the activities of INTACT project, receiving funding from the European Union Seventh Framework Programme (FP7/2007-2013) under grant agreement ${ }^{\circ}$ FP7-SEC-2013-1-606799. The information and views set out in this paper are those of the authors and do not necessarily reflect the opinion of the European Union.

We acknowledge the World Climate Research Programme's Working Group on Regional Climate, and the Working Group on Coupled Modelling, former coordinating body of CORDEX and responsible panel for CMIP5. 


\section{Figure captions}

Figure 1 EA (a) and uncertainty range (b) of Rx1day relative anomaly (2071-2100 against 1981-2010) obtained using the $10 \mathrm{RCMs}$ considered under RCP4.5. Uncertainty ranges are plotted using three circles indicating the mean minus standard deviation, mean and mean plus standard deviation of the ensemble, from the interior to the outermost parts, respectively.

Figure 2 Observed (red triangles), direct output (blank dots) and bias corrected (black dots) Rx 1day over the current period for the 10 RCMs.

Figure 3 Rx1day (a-b), RT(REWS) (c-d) and ET(R1-R59) (e-f) anomalies calculated by the REA with bias correction. Over the observed period 1981-2010, the values are Rx1day = $92 \mathrm{~mm}, \mathrm{RT}(\mathrm{REWS})=10 \mathrm{y}, \mathrm{ET}(\mathrm{R} 1$ $\mathrm{R} 59)=2.5$ events/y. Left column refers to RCP4.5 while right column to RCP8.5. Red and blue shaded areas the drier and wetter conditions, respectively, compared to the actual ones.

Figure 4 Rx1day anomalies calculated using the three levels of analysis (EA, REA without bias correction, REA with bias correction) under (a) RCP4.5 and (b) RCP8.5 on 2071-2100.

Figure 5 EA (a-c) and uncertainty range (b-d) of Rx1day (a-b) and FGx1day (c-d) relative anomaly (2071-2100 against 1981-2010) obtained using the 10 RCMs considered under RCP4.5. Results are plotted as Figure 2

Figure 6 Observed (red triangles), direct output (blank dots) and bias corrected (black dots) Rx1day (a) and FGx1day(b) over the current period for the 10 RCMs considered.

Figure 7 Rx1day(RT10y) (a-b), Rx1week(RT10y) (c-d) and FGx1day (e-f) anomalies calculated by the REA with bias correction. On observed 1981-2010, Rx1day(RT10y) = $52 \mathrm{~mm}, \mathrm{Rx} 1$ week(RT10y) = $110 \mathrm{~mm}, \mathrm{FGx} 1 \mathrm{day}$ $=12.9 \mathrm{~m} / \mathrm{s}$. Left column refers to RCP4.5 while right column to RCP8.5.

\section{Table captions}

Table 1 Available Euro-CORDEX simulations at a $0.11^{\circ}$ resolution $(\sim 12 \mathrm{~km})$ over Europe. The providing institution and the GCM and RCMs used in this case are indicated. 


\section{References}

Bucchignani E, Montesarchio M, Zollo AL, Mercogliano P (2015) High-resolution climate simulations with COSMOCLM over Italy: performance evaluation and climate projections for the XXI century. Int J Climatol. doi:10.1002/joc.4379

Ciervo F, Rianna G, Mercogliano P, Papa MN (2017) Effects of climate change on shallow landslides in a small coastal catchment in southern Italy. Landslides 14(3):1043-1055. Doi:10.1007/s10346-016-0743-1

De Vita P, Piscopo V (2002) Influences of hydrological and hydrogeological conditions on debris flows in peri-vesuvian hillslopes. Nat Haz Earth Syst Sc 2: 27-35. doi:10.5194/nhess-2-27-2002

EEA (2017) Climate change adaptation and disaster risk reduction in Europe. EEA Report No 15/2017. ISBN:978-929213-893-6

European Commission (2008) Council Directive 2008/114/EC of 8 December 2008 on the identification and designation of European critical infrastructures and the assessment of the need to improve their protection. Available from http://eurlex.europa.eu/LexUriServ/LexUriServ.do?uri=OJ:L:2008:345:0075:0082:EN:PDF

Giorgi F, Mearns LO (2002) Calculation of Average, Uncertainty Range, and Reliability of Regional Climate Changes from AOGCM Simulations via the "Reliability Ensemble Averaging"' (REA) Method. J Clim 15:1141-1158. doi: 10.1175/1520-0442(2002)015<1141:COAURA >2.0.CO;2

Giorgi F, Mearns LO (2003) Probability of regional climate change based on the Reliability Ensemble Averaging (REA) method. Geophys Res Lett 30(12): 1629, doi:10.1029/2003GL017130

Gutiérrez JM, et al (2017) An intercomparison of a large ensemble of statistical downscaling methods for Europe: Overall results from the VALUE perfect predictor cross-validation experiment. Int J Climatol, in print

Jacob D, Petersen J, Eggert B, et al (2014) EURO-CORDEX: new high-resolution climate change projections for European impact research. Reg Environ Chang 14:563-578. doi:10.1007/s10113-013-0499-2

Knutti R, Furrer R, Tebaldi C, Cermak J, Meehl GA (2010) Challenges in combining projections from multiple climate models. J Clim 23:2739-2758. doi: 10.1175/2009JCLI3361.1

Maraun D (2016) Bias Correcting Climate Change Simulations - A Critical Review. Curr Clim Chang Rep 2(4): 211220. doi:10.1007/s40641-016-0050-x

Maraun D, Shepherd TG, Widmann M, et al (2017) Towards process-informed bias correction of climate change simulations. Nat Clim Chang 7:764-773. doi:10.1038/nclimate3418

Meinshausen M, Smith SJ, Calvin K, et al (2011) The RCP greenhouse gas concentrations and their extensions from 1765 to 2300. Clim Chang 109:213-24. doi:10.1007/s10584-011-0156-z

O’Gorman PA (2015) Precipitation Extremes Under Climate Change. Curr Clim Chang Rep 1(2):49-59. doi:10.1007/s40641-015-0009-3

Pagano L, Picarelli L, Rianna G, Urciuoli G (2010) A simplified approach for timely prediction of precipitation-induced landslides in unsaturated pyroclastic soils. Landslides 7(3):273-289. doi:10.1007/s10346-010-0216-X

Räisänen J, Palmer TN (2001) A probability and decision-model analysis of a multi-model ensemble of climate change simulations, J Clim 14:3212-3226. doi:10.1175/1520-0442(2001)014<3212:APADMA>2.0.CO;2

Reder A, Rianna G, Mercogliano P, Pagano L (2016) Assessing the potential effects of Climate Changes on landslide phenomena affecting pyroclastic covers in Nocera area (Southern Italy). Proc Earth Planet Sc 16:166-176. doi:10.1016/j.proeps.2016.10.018

Reder A, Rianna G, Pagano L (2018) Physically based approaches incorporating evaporation for early warning predictions of rainfall-induced landslides. Nat Haz and Earth Syst Sc 18:613-631, doi: 10.5194/nhess-18-613-2018

Rianna G, Reder A, Mercogliano P, Pagano L (2017a) Evaluation of Variations in Frequency of Landslide Events Affecting Pyroclastic Covers in Campania Region under the Effect of Climate Changes. Hydrol 4(3):34. doi: 10.3390/hydrology4030034 
Rianna G, Reder A, Villani V, Mercogliano P (2017b) Variations in landslide frequency due to Climate Changes through high resolution Euro-CORDEX Ensemble. In: Mikoš M, Casagli N, Yin Y, Sassa K (eds) Advancing Culture of Living with Landslides. WLF 2017. Springer, Cham; pp 237-242. doi:10.1007/978-3-319-53485-5_27

Sham Bhat K, Haran M, Terando A, Keller K (2011) Climate Projections Using Bayesian Model Averaging and SpaceTime Dependence. J Agric Biol Environ Stat 16(4):606-628. doi:10.1007/s13253-011-0069-3

Stephenson DB (2008) Definition, diagnosis, and origin of extreme weather and climate events. In: Diaz HF, Murnane RJ (eds) Climate Extremes and Society. Cambridge University Press, pp. 11-22.

UNISDR (2015) Sendai Framework for Disaster Risk Reduction 2015-2030. United Nations Office for Disaster Risk Reduction: Geneva, Switzerland

van Ruiten K, Bles T, Kiel J (2016). EU-INTACT-case studies: Impact of extreme weather on critical Infrastructure. FLOODrisk 2016 - E3S Web of Conferences 7:07001. doi:10.1051/e3sconf/20160707001

Villani V, Rianna G, Mercogliano P, Zollo AL (2015) Statistical approaches versus weather generator to downscale RCM outputs to slope scale for stability assessment: a comparison of performances. Electron J Geotech Eng, 20(4):1495-1515. doi:10.4090/juee.2013.v8n2.142-154

Wehner M (2013). Methods of Projecting Future Changes in Extremes. In: AghaKouchak A, Easterling D, Hsu K, Schubert S, Sorooshian S (eds) Extremes in a Changing Climate Detection, Analysis and Uncertainty. Springer, London, pp. 223-237

Wilby RL (2017) Climate Change in Practice Topics for Discussion with Group Exercises. Cambridge University Press. doi: $10.1017 / 9781316534588$

Zollo AL, Rillo V, Bucchignani E, Montesarchio M, Mercogliano P (2015) Extreme temperature and precipitation events over Italy: assessment of high resolution simulations with COSMO-CLM and future scenarios. Int J Climatol. doi:10.1002/joc.4401 

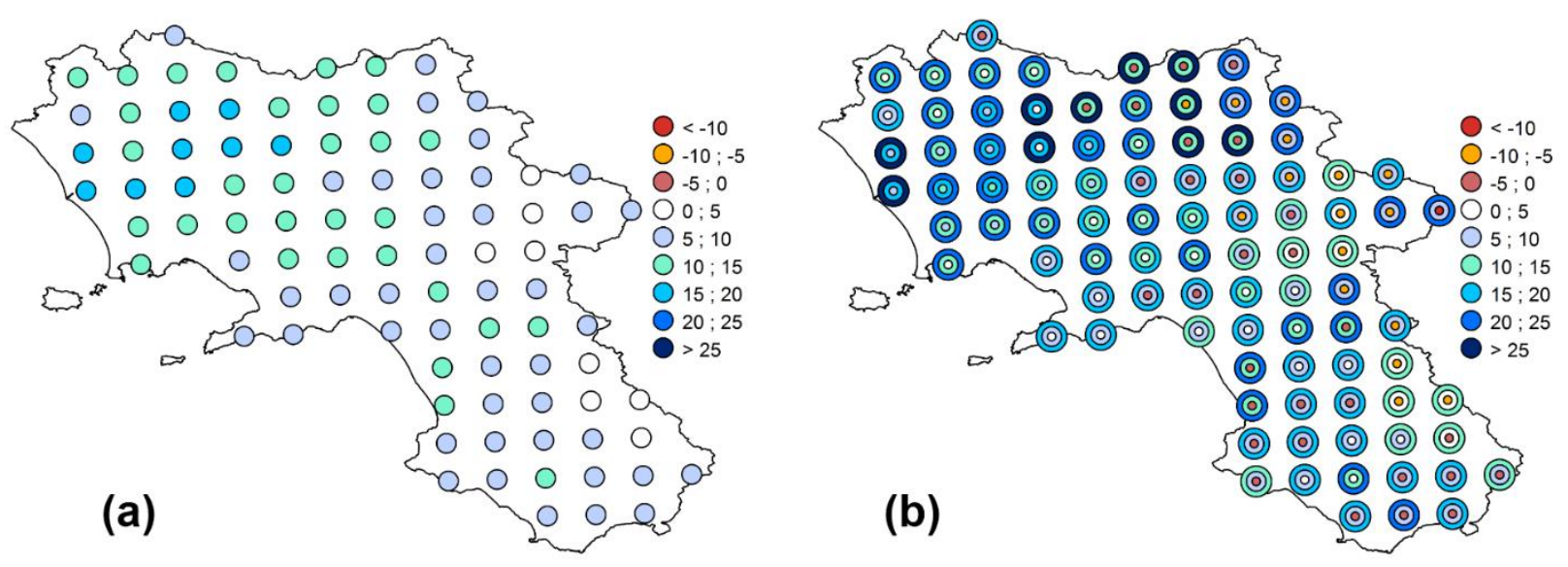

Figure 1 EA (a) and uncertainty range (b) of Rx1day relative anomaly (2071-2100 against 1981-2010) obtained using the $10 \mathrm{RCMs}$ considered under RCP4.5. Uncertainty ranges are plotted using three circles indicating the mean minus standard deviation, mean and mean plus standard deviation of the ensemble, from the interior to the outermost parts, respectively.

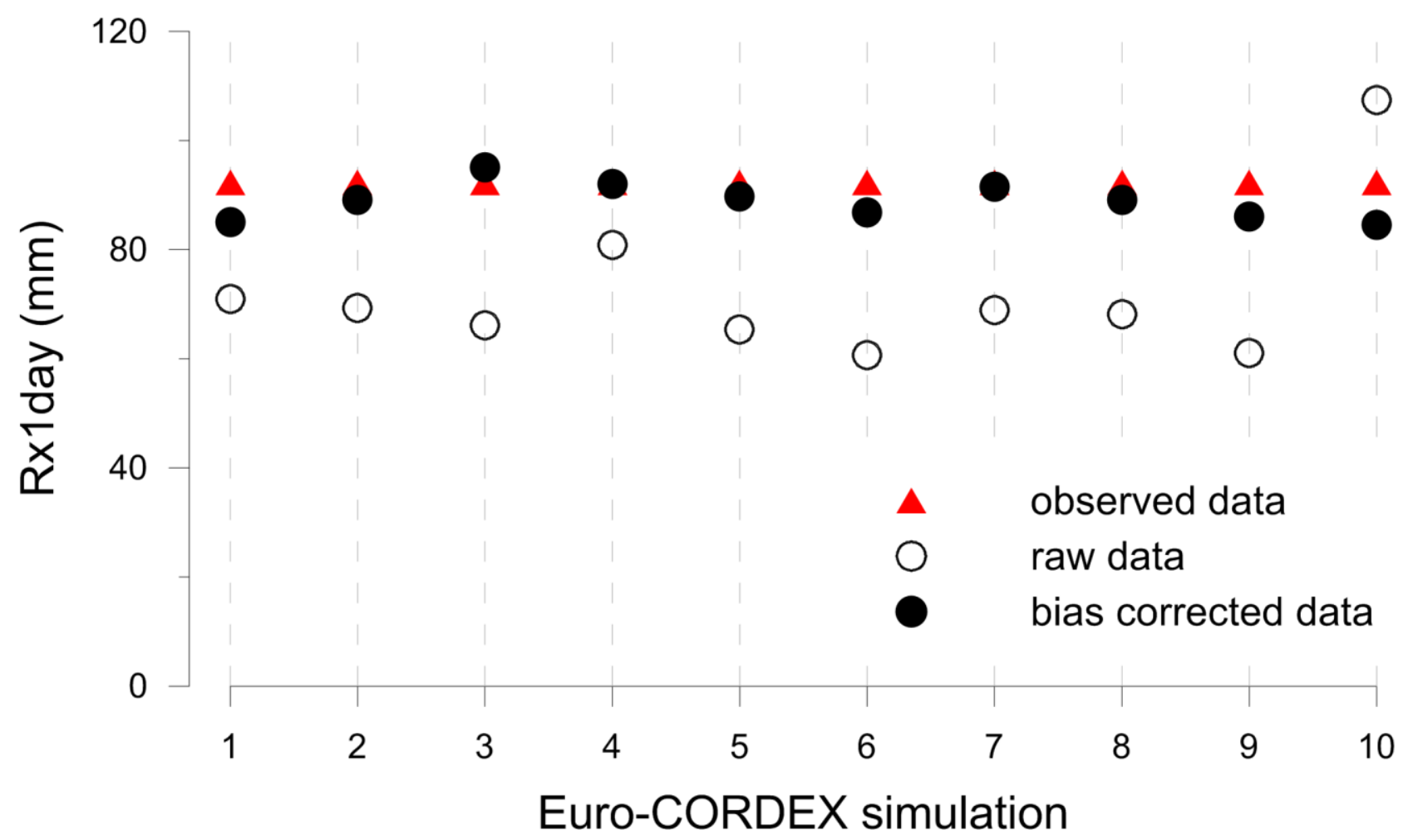

Figure 2 Observed (red triangles), direct output (blank dots) and bias corrected (black dots) Rx1day over the current period for the 10 RCMs. 


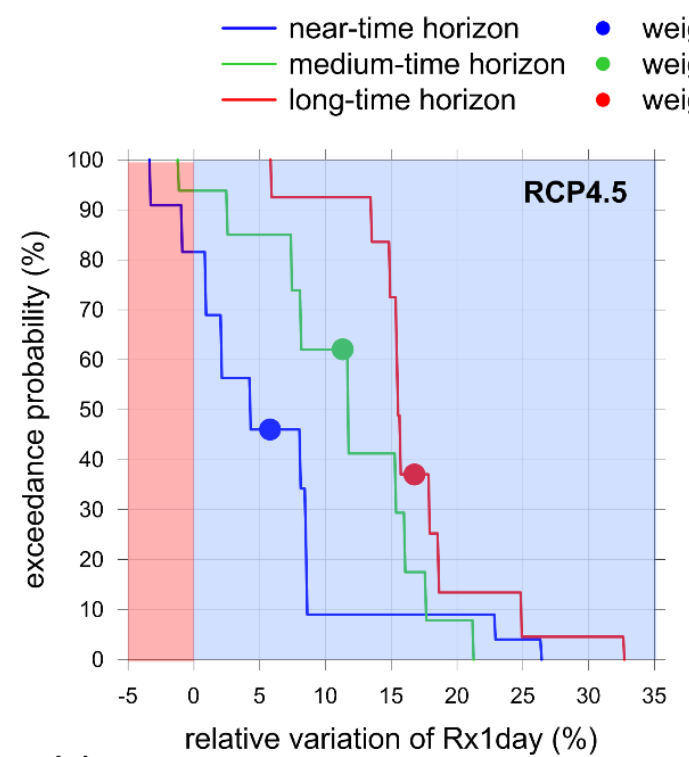

(a)

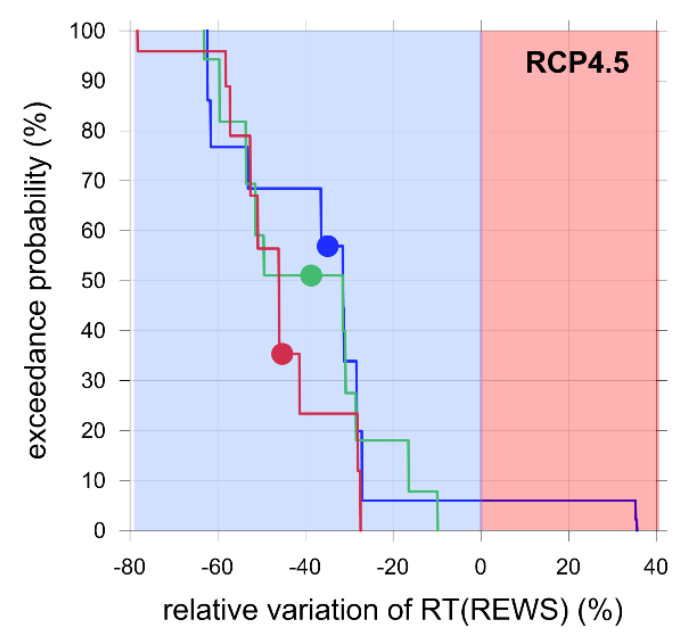

(c)

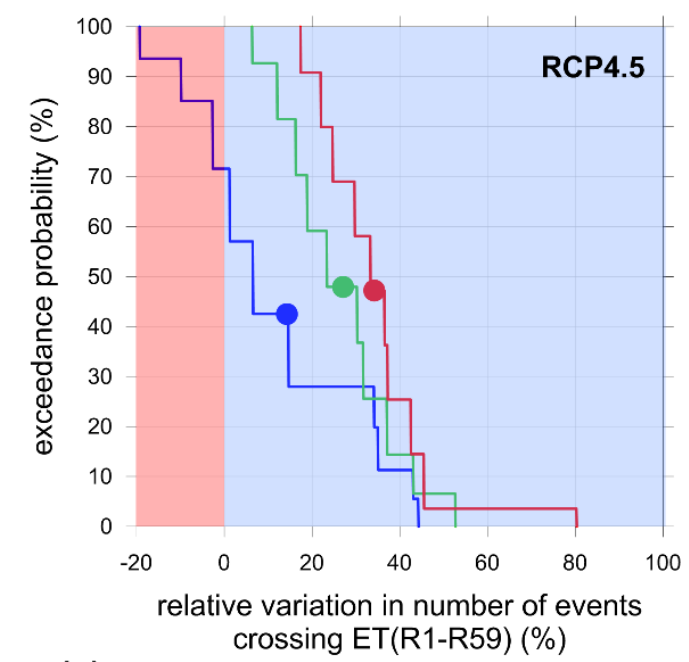

(e)

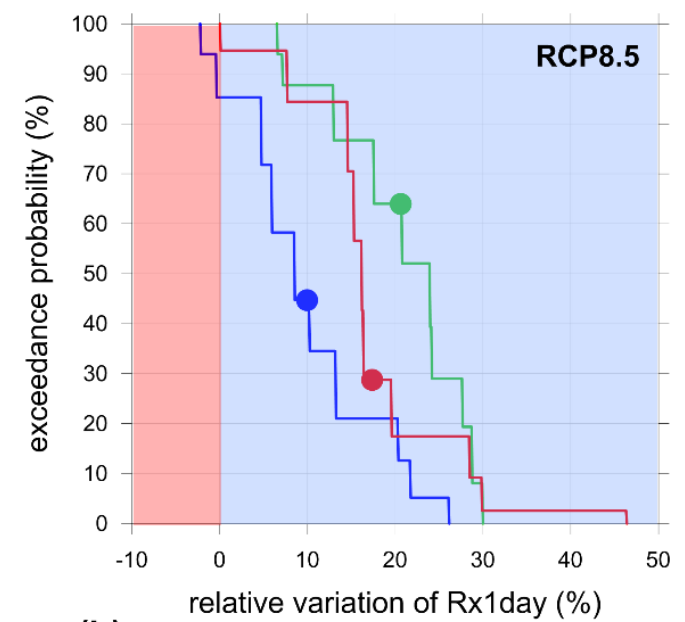

(b)

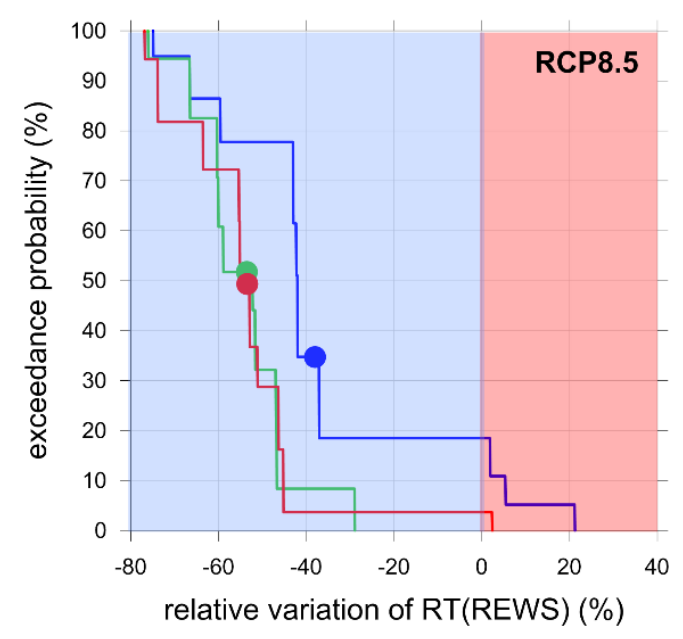

(d)

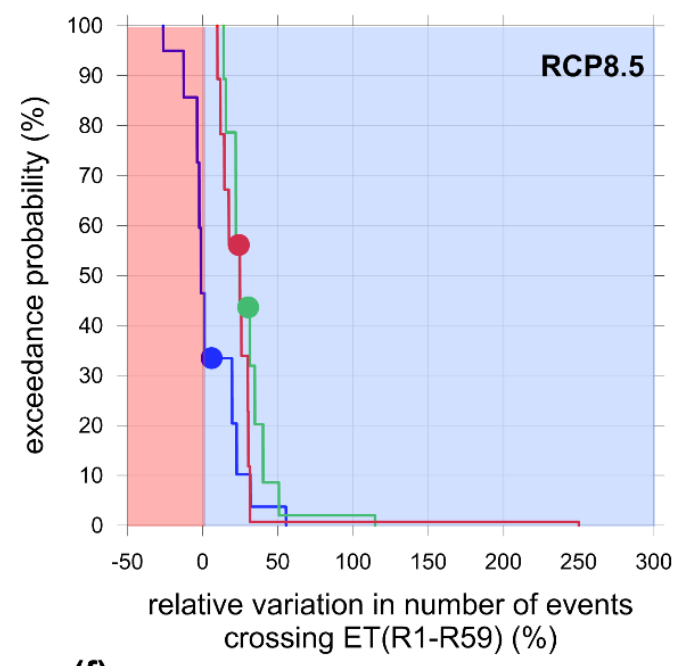

(f)

Figure 3 Rx1day (a-b), RT(REWS) (c-d) and ET(R1-R59) (e-f) anomalies calculated by the REA with bias correction. Over the observed period 1981-2010, the values are Rx1day $=92 \mathrm{~mm}, \mathrm{RT}(\mathrm{REWS})=10 \mathrm{y}, \mathrm{ET}(\mathrm{R} 1-\mathrm{R} 59)=2.5 \mathrm{events} / \mathrm{y}$. Left column refers to RCP4.5 while right column to RCP8.5. Red and blue shaded areas the drier and wetter conditions, respectively, compared to the actual ones. 


\section{— Level A - weighted multi-model mean (Level A) \\ Level B $\quad$ weighted multi-model mean (Level B) \\ Level C • weighted multi-model mean (Level C)}

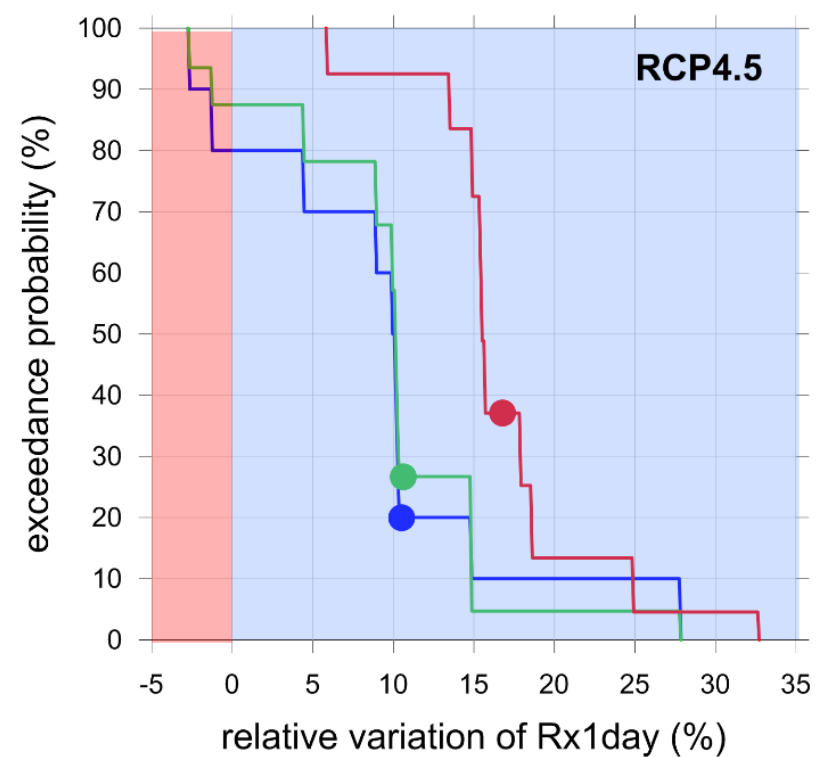

(a)

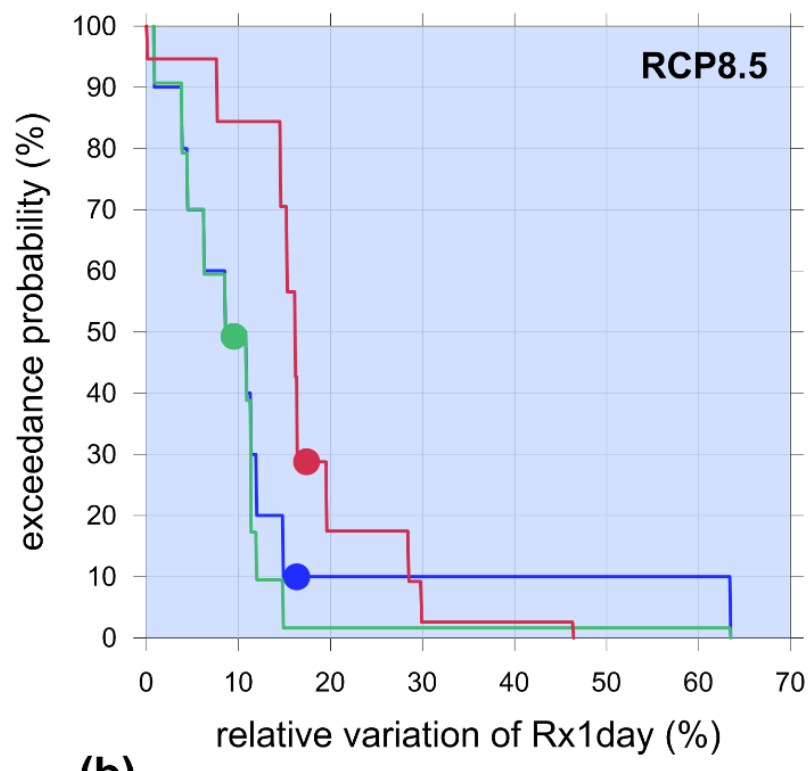

(b)

Figure 4 Rx1day anomalies calculated using the three levels of analysis (EA, REA without bias correction, REA with bias correction) under (a) RCP4.5 and (b) RCP8.5 on 2071-2100.

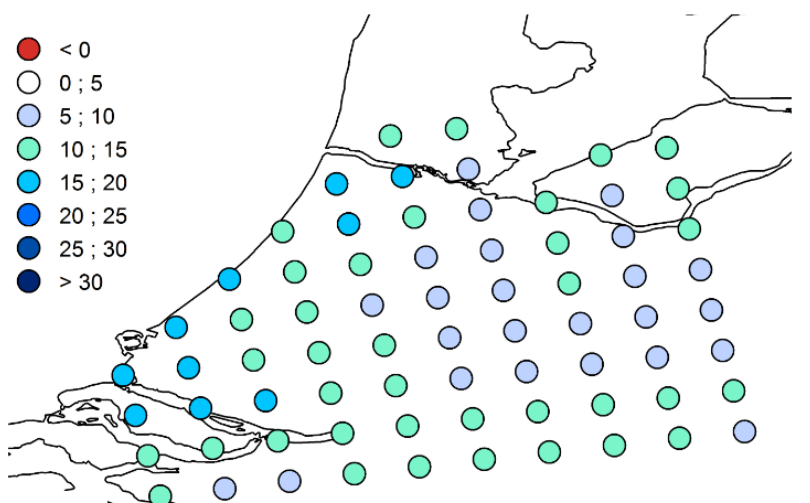

(a)

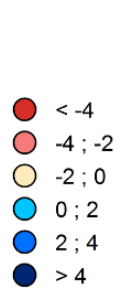

(b)

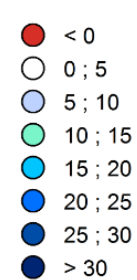

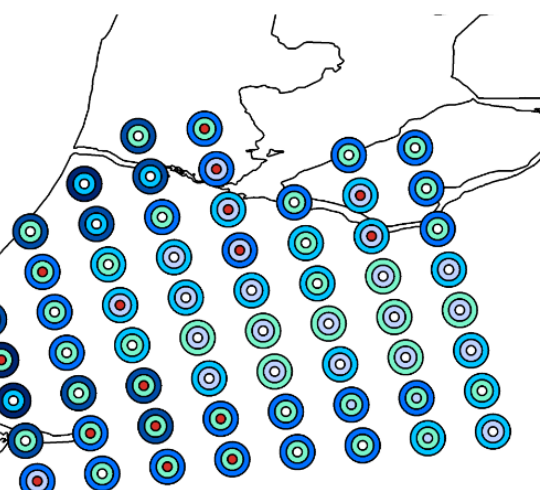
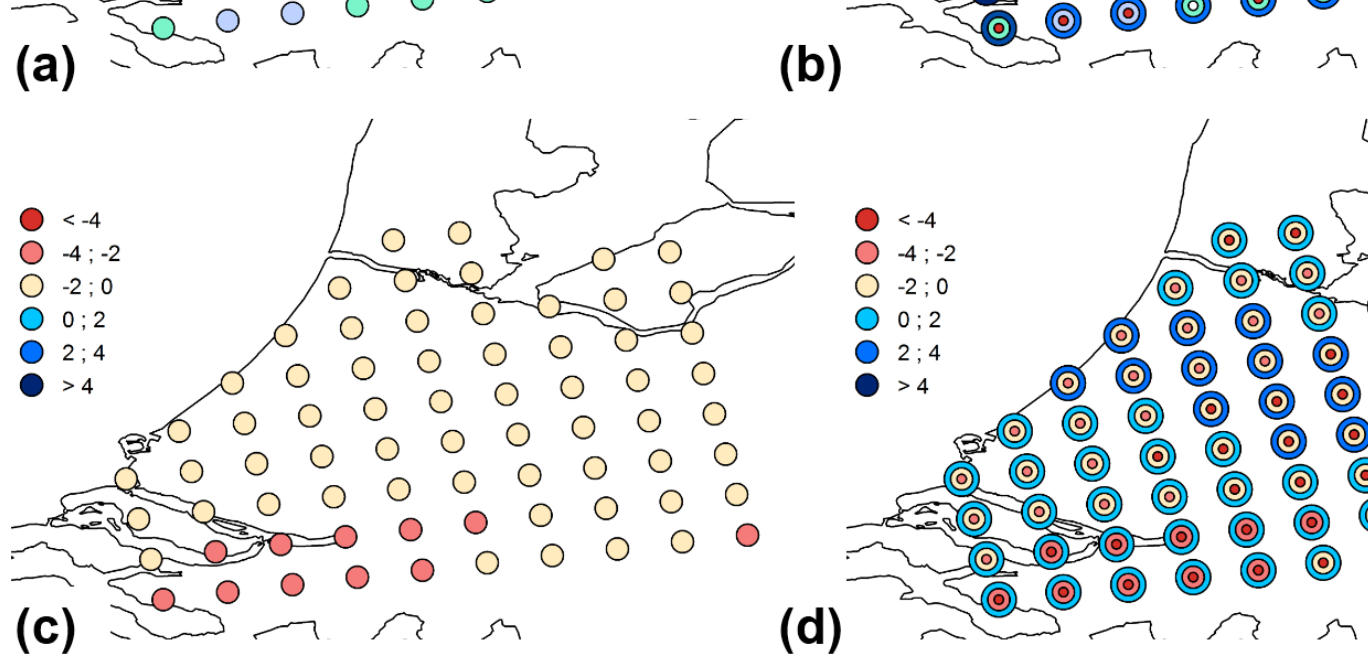

(d)

$\begin{array}{ll}0 & <-4 \\ 0 & -4 ;-2\end{array}$

O $-2 ; 0$

O $0 ; 2$

$2 ; 4$
$>$ 
Figure 5 EA (a-c) and uncertainty range (b-d) of Rx1day (a-b) and FGx1day (c-d) relative anomaly (2071-2100 against 1981-2010) obtained using the 10 RCMs considered under RCP4.5. Results are plotted as Figure 2
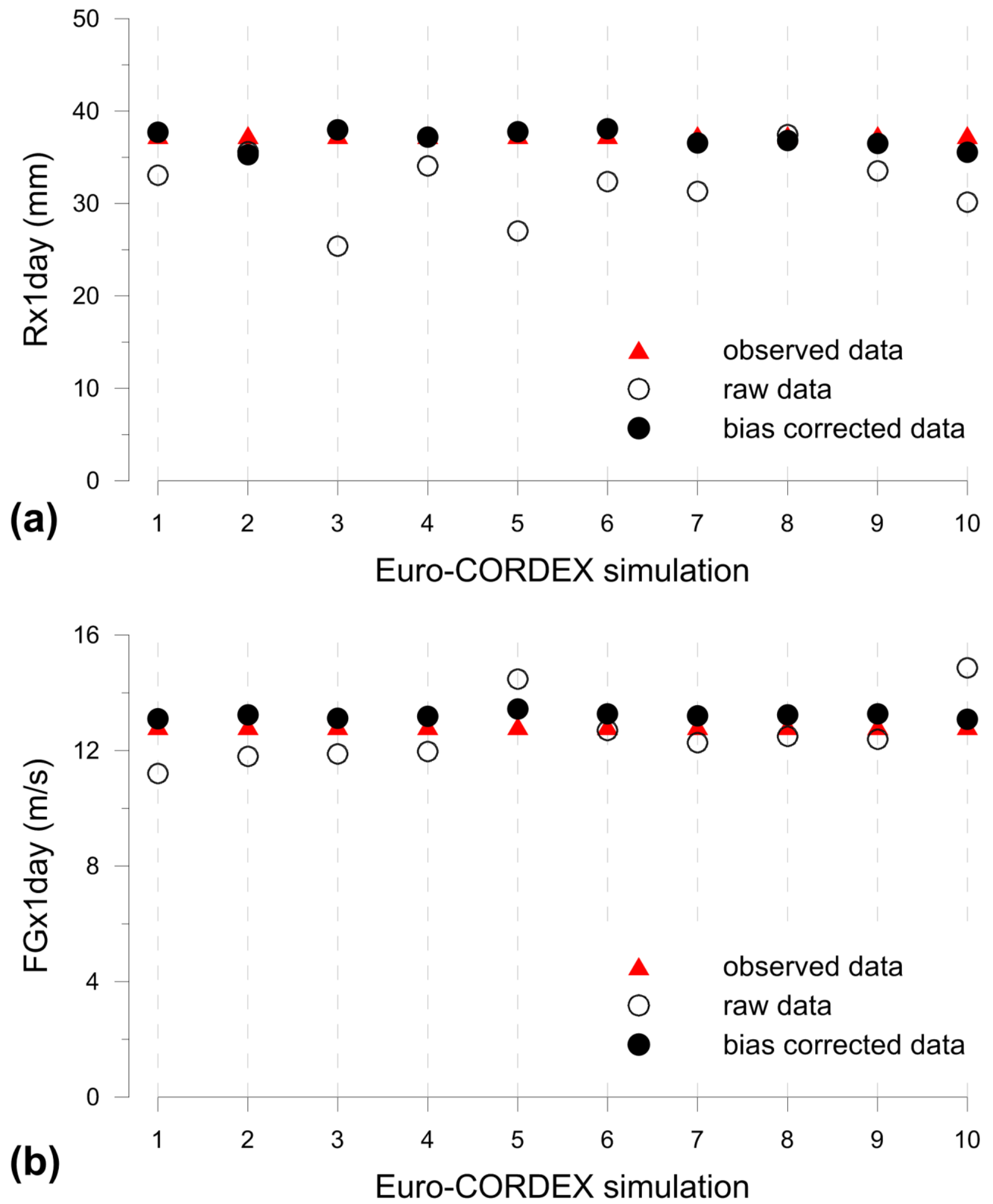

Figure 6 Observed (red triangles), direct output (blank dots) and bias corrected (black dots) Rx1day (a) and FGx1day(b) over the current period for the 10 RCMs considered. 


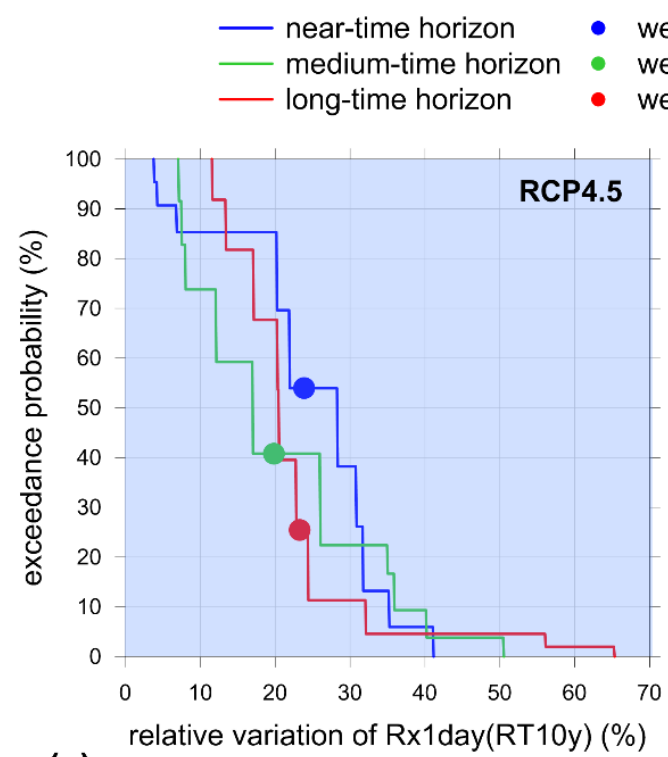

(a)

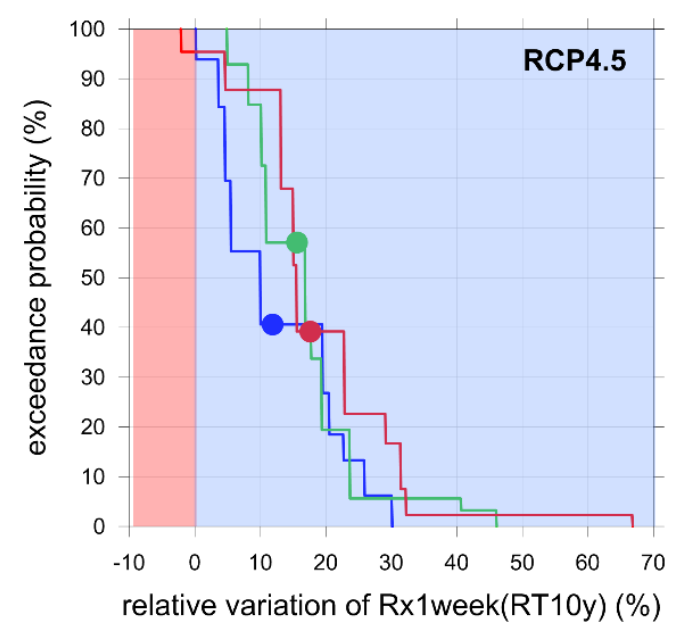

(c)

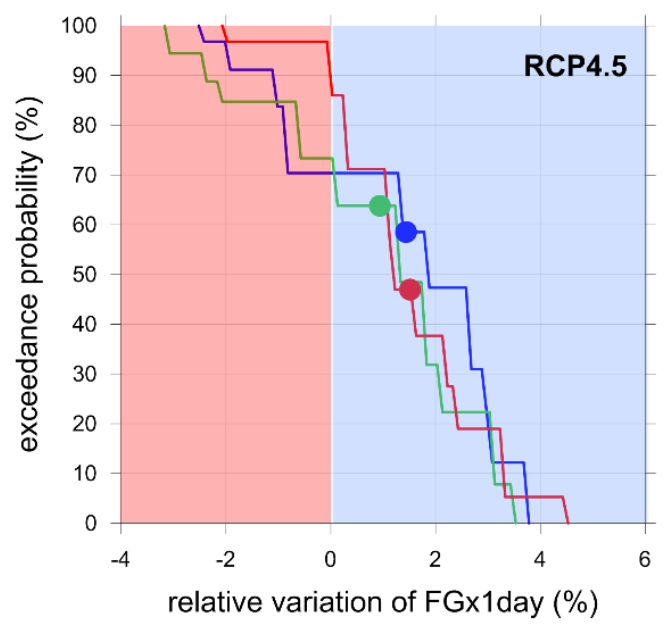

(e)

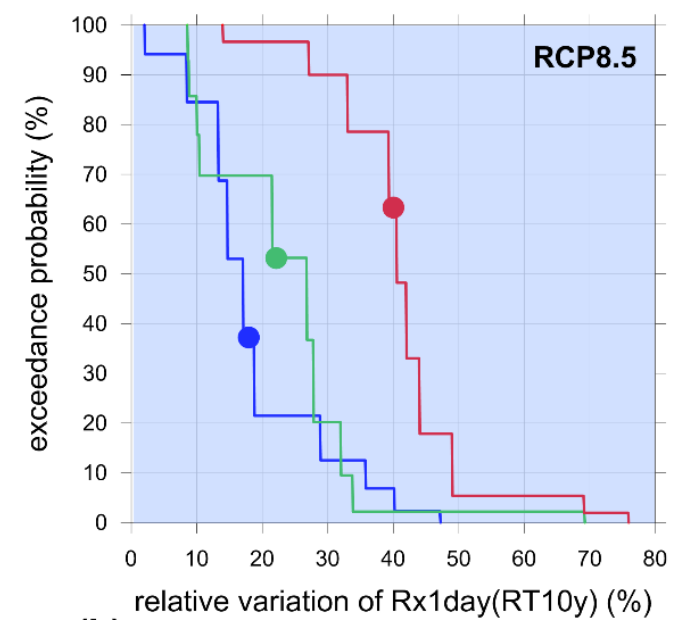

(b)

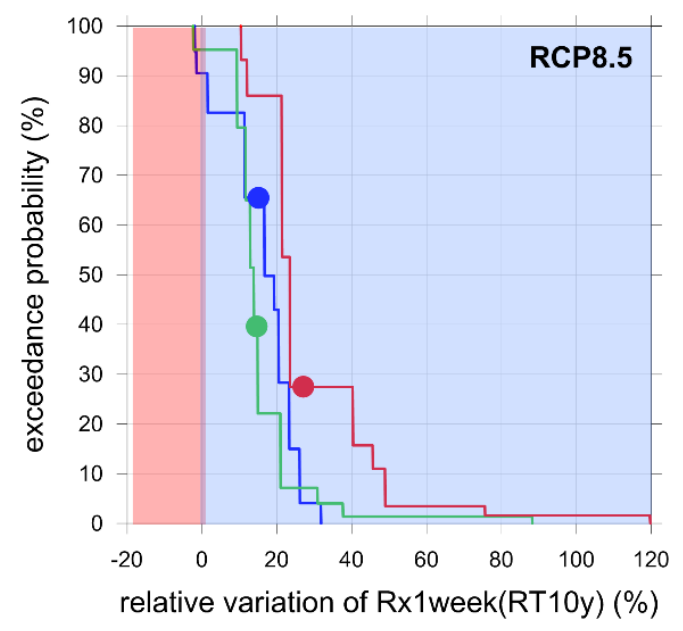

(d)

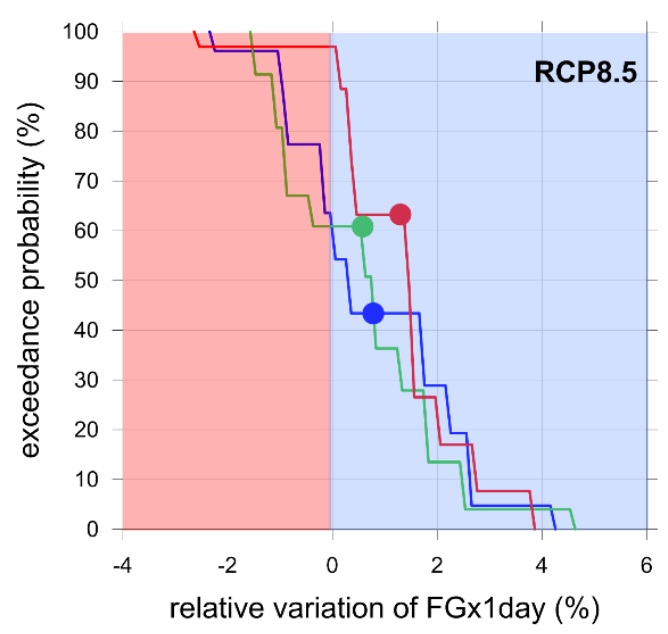

(f)

Figure 7 Rx1day(RT10y) (a-b), Rx1week(RT10y) (c-d) and FGx1day (e-f) anomalies calculated by the REA with bias correction. On observed 1981-2010, Rx1day(RT10y) $=52 \mathrm{~mm}, \mathrm{Rx} 1 \mathrm{week}(\mathrm{RT} 10 \mathrm{y})=110 \mathrm{~mm}$, FGx1day $=12.9 \mathrm{~m} / \mathrm{s}$. Left column refers to RCP4.5 while right column to RCP8.5. 
Table 1 Available Euro-CORDEX simulations at a $0.11^{\circ}$ resolution $(\sim 12 \mathrm{~km})$ over Europe. The providing institution and the GCM and RCMs used in this case are indicated.

\begin{tabular}{|c|c|c|c|} 
Code & Institution & GCM & RCM \\
1 & CLMcom & CNRM-CM5_r1i1p1 & CCLM4-8-17_v1 \\
\hline 2 & SMHI & CNRM-CM5_r1i1p1 & RCA4_v1 \\
3 & CLmcom & EC-EARTH_r12i1p1 & CCLM4-8-17_v1 \\
\hline 4 & DMI & EC-EARTH_r3i1p1 & HIRHAM5_v1 \\
\hline 5 & KNMI & EC-EARTH_r1i1p1 & RACMO22E_v1 \\
\hline 6 & SMHI & EC-EARTH_r12i1p1 & RCA4_v1 \\
\hline 7 & CLMcom & MPI-ESM-LR_r1i1p1 & CCLM4-8-17_v1 \\
\hline 8 & SMHI & MPI-ESM-LR_r1i1p1 & RCA4_v1 \\
\hline 9 & SMHI & IPSL-CM5A-MR_r1i1p1 & RCA4_v1 \\
\hline 10 & IPSL-INERIS & IPSL-CM5A-MR_r1i1p1 & WRF331F_v1 \\
\hline
\end{tabular}




\section{Ensemble Averaging (EA) method}

The Ensemble Averaging (EA) estimates the variation of a generic EWI through the direct ensemble average of all model simulations, assigning then the same weight to each model and neglecting a reliability criterion:

$$
\overline{\Delta x}=\frac{1}{n} \sum_{i=1, n} \Delta x_{i}
$$

where $\overline{\Delta x}$ is the averaged variation of a generic indicator $x, n$ is the total number of model simulations and $\Delta x_{i} \quad$ represent the changes simulated by each model. The uncertainty range is computed as $\overline{\Delta x} \pm \delta_{\Delta x}$, where $\delta_{\Delta x}$ represents the root-mean-square difference:

$$
\delta_{\Delta x}=\left[\frac{1}{n} \sum_{i=1, n}\left(\Delta x_{i}-\overline{\Delta x}\right)^{2}\right]^{1 / 2}
$$

\section{Reliability Ensemble Averaging (REA) method}

The Reliability Ensemble Averaging (REA) (Giorgi and Mearns 2002) weights the output from multi-model ensembles on the basis of model performance and scenario consistency. For each model $i$, a reliability factor $R_{i}$ is estimated as:

$$
R_{i}=\left[\left(R_{b, i}\right)^{m}\left(R_{d, i}\right)^{n}\right]^{\frac{1}{m n}}=\left[\left(\frac{\varepsilon_{T}}{\left|\left(B_{T, i}\right)\right|}\right)^{m}\left(\frac{\varepsilon_{T}}{\|\left(D_{T, i}\right) \mid}\right)^{n}\right] \frac{1}{m n}
$$

where $R_{b, i}$ is a factor that quantifies model performance as a function of the model bias $B_{T, i}$ (difference between simulated and observed EWI over the reference period) and $R_{d, i}$ is a factor that quantifies model convergence in terms of the distance $D_{T, i}$ (difference between simulated and mean ensemble deltas -future minus reference projected values-); $\quad \varepsilon_{T}$ represents a measure of the natural variability of the EWI (computed in our analysis through a bootstrapping technique on 1000 iterations as standard error from the mean); finally, $m \quad$ and

$n$ are weight parameters (assumed as 1 in our analysis, that is model performance and model convergence criteria are characterized by equal weight). Note that this approach requires the availability of local observations for the target EWIs on the region under study.

Given the weight of each simulation model, $\overline{\Delta x}$ is expressed as:

$$
\overline{\Delta x}=\frac{\sum_{i=1, n} R_{i} \Delta x_{i}}{\sum_{i=1, n} R_{i}}
$$

Also in this case, the uncertainty range is computed as $\overline{\Delta x} \pm \delta_{\Delta x}$, where $\delta_{\Delta x}$ represents the uncertainty, quantified through the weight root-mean-square difference as: 


$$
\delta_{\Delta x}=\left[\frac{\sum_{i=1, n} R_{i}\left(\Delta x_{i}-\overline{\Delta x}\right)^{2}}{\sum_{i=1, n} R_{i}}\right]^{1 / 2}
$$

\section{Probability approach}

The probability of a climate change exceeding a certain threshold

$\Delta x_{t h}$ is given by the weighted sum of $\mathrm{Ri}$ associated with models estimating an equal or higher variation:

$$
P r_{m \Delta x_{t h}}=\sum_{i} P r_{m i}=\sum_{i} \frac{R_{i}}{\sum_{i=1}^{n} R_{i}} \quad \Delta x_{i} \geq \Delta x_{t h}
$$

Eq. (6) can be adopted for both EA and REA (assuming all the $R_{i}$ are equal to one). 